\title{
Kierkegaard. Existence and Identity in a Post-Secular World, Alastair Hannay
}

Matías Tapia Wende ${ }^{1}$

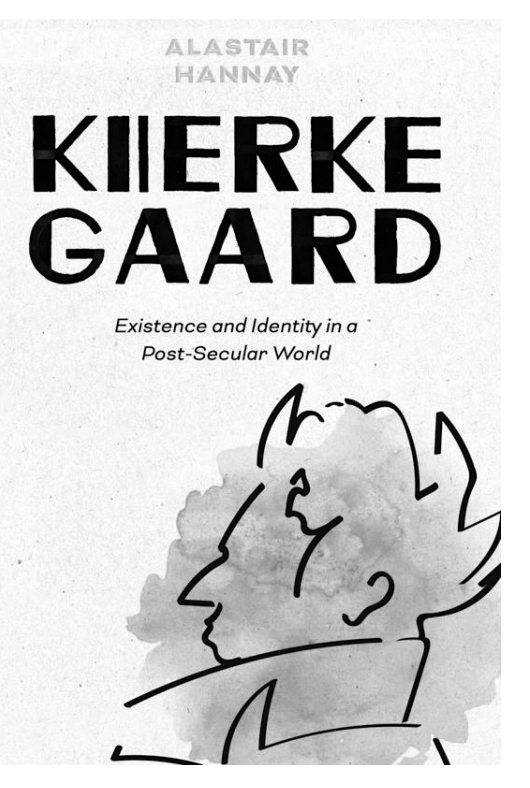

Alastair Hannay. Kierkegaard. Existence and Identity in a Post-Secular World. Londres y Nueva York: Bloombury, 2020, 116 pp.
Kierkegaard. Existence and Identity in a Post-Secular World es un libro de Alastair Hannay, profesor emérito de la Universidad de Oslo, publicado por la editorial Bloomsbury, en mayo de 2020. Hannay es un destacado traductor y especialista kierkegaardiano; ha traducido al inglés $O$ lo uno o lo otro, Temor y temblor, Una reseña literaria y La enfermedad mortal. Asimismo, participó junto con Gordon Marino en la edición del Cambridge Companion to Kierkegaard (Cambridge

Esta reseña fue escrita gracias al apoyo de ANID-Chile Proyecto Fondecyt Postdoctorado N.o 3200167 El pensamiento político de Kierkegaard y sus implicancias para el debate contemporáneo sobre Estado e identidad, con el patrocinio de Manfred Svensson y la Universidad de Los Andes, Chile. 
University Press, 1998) y formó parte del equipo que condujo la nueva versión inglesa de los papeles personales de Kierkegaard (Princeton University Press, 2006-2020). Cabe mencionar el lugar que ocupa su Kierkegaard: A Biography (Cambridge University Press, 2001), un recuento de la vida y obra de Kierkegaard desde un enfoque marcadamente intelectual. Este último fue traducido por Nassim Bravo y publicado por la editorial de la Universidad Iberoamericana en 2010.

Kierkegaard. Existence and Identity in a Post-Secular World consta de seis capítulos. A éstos se suman una introducción, notas, bibliografía y un índice de nombres y de materias. En un recorrido más bien libre, Hannay se propone vincular la preocupación de Kierkegaard por la individualidad con la creciente fuerza que ha cobrado la política de la identidad. El autor asume que es posible encontrar en Kierkegaard una preocupación por modular a las personas para "hacer que nuestras diferencias trabajen por el bien común". ${ }^{2}$ El detalle es que la perspectiva de Kierkegaard, en la lectura de Hannay, tiene un punto de partida distinto al de la política identitaria. Si para los militantes de esta última el "nosotros" ecuménico social borra cualquier diferencia, para Kierkegaard este pronombre funciona como obstáculo para la formación ante todo individual. Para Kierkegaard, una reorientación en este sentido tiene raíces en la narrativa cristiana.

El primer capítulo se titula "El mensaje y el mensajero". Hannay discute la relación entre Kierkegaard y su intrincada obra. A través de su juego de pseudónimos, Kierkegaard mismo consiguió esconder al emisor originario y poner en relevancia el mensaje. En esta tensión literaria se refleja, según Hannay, la profunda comprensión existencial del pensador danés. Tal como después lo será para Heidegger y Sartre, defiende Hannay, para Kierkegaard "la existencia es el medio conscientemente secular en el que en específico los seres humanos 
enfrentan la tarea de 'llegar a ser sí mismos". ${ }^{3}$ No se debe pasar por alto que Hannay habla de un instrumento —o un hábitat - secular. El mundo en que Kierkegaard pone al individuo debe entenderse como un mundo a ser compartido. La tarea, por su parte, está determinada para Hannay como un despliegue de la libertad espiritual de cada persona. Sin perder de vista el influjo cristiano en Kierkegaard, lo que parece estar perfilándose en esta reflexión es una comprensión sociopolítica de lo religioso, como uno de los modos de asumir la labor de existir.

Justamente "Ser uno mismo" es el título del segundo capítulo, el más breve del libro. Hannay afirma que Kierkegaard presintió un ánimo que marcó luego a Marx, Weber y Freud: el desafío de la identidad. Al desligarse del elitismo cultural de la época de oro de Dinamarca, Kierkegaard se volcó a prevenir la propagación de la debacle subjetiva en el ocaso de la modernidad. El énfasis en el cristianismo es una luz de esperanza. "El mensaje de Kierkegaard es que sus palabras [las del cristianismo] deberían entenderse en un nivel en el que la carencia de hogar existencial se enfrenta tal como es". ${ }^{4}$ Kierkegaard desecha las verdades de la ciencia, de la filosofía y de la política como fuentes para construirse a sí mismo. La proyección hacia su comprensión de la individualidad es la persecución de la unidad, de la articulación del yo bajo una misma luz.

El siguiente capítulo es "Lo eterno en un parpadeo". Las principales referencias de Hannay en este apartado son Migajas filosóficas y el Postscriptum, de 1844 y 1846 respectivamente. Estas dos obras aparecieron firmadas por el pseudónimo Johannes Climacus y cuentan con Kierkegaard como editor ficticio. Climacus es un férreo crítico de Hegel y los hegelianos. A esta corriente, supuestamente abstracta y representacional, Climacus opone la relación dialéctica de la idea en la existencia concreta del individuo. Este punto de unión es el instante kierkegaardiano (Øieblikket, un abrir y cerrar de ojos) posibilitado por la fe en tanto gracia divina y decisión subjetiva. 
Hannay entiende que Kierkegaard lucha, a través de Climacus, con la búsqueda moderna de certeza. Entre esta pared y la del positivismo contemporáneo, la empresa del individuo construida por Kierkegaard se coloca frente a las incertidumbres de la existencia. Ni la estética ni la ética ni la religión resisten la exigencia objetiva. Menos el sujeto respecto de su situación concreta. El creyente, defiende Hannay, es un sujeto que pone en juego su fe no como un mecanismo de protección "cuando el razonamiento epistémico normal se queda corto". ${ }^{5}$ Lo que ocurre, más bien, es una reconciliación integral ante los aspectos irreconciliables de la vida. De este movimiento emerge la personalidad. El asunto es que esta persona resultante, para Kierkegaard, se determina en su relación con Dios. La política, las mayorías, los otros, en general, devienen indiferentes. Hannay esboza ya la pregunta sobre cómo compartir la existencia.

El cuarto capítulo es "Comulgar con Dios”. Hannay acerca a Hegel y a Kierkegaard en cuanto a "pensar en términos de una teleología o de la idea de que existe un fin o un propósito en la vida". 6 Para Hegel esto implica la presencia del espíritu en lo concreto. Para Kierkegaard, el asunto se trata de acceder subjetivamente a lo eterno a través de la narrativa cristiana y dejar de depender de lo histórico. Kierkegaard no se desapega del individuo, constituido como tal sólo frente a Dios. La tarea de construir la personalidad se logra en la presencia de la personalidad absoluta. En parentesco ahora con Schelling, Hannay muestra a Kierkegaard resignificando la diversidad humana. La posibilidad de autoconciencia subjetiva es lo que nos diversifica $y$, al mismo tiempo, inicia nuestro camino hacia la unidad. En este sentido, el amor y la fe funcionan como órganos que cruzan la razón objetiva. Hannay se esmera en mostrar que Kierkegaard no hablaba desde fuera. La paz, armonía y alegría que un físico encuentra en la teoría, Kierkegaard la halla en la deidad: "Es sólo en la interioridad que [el] sentido de la totalidad se apodera de una persona 
y la religión adquiere realmente importancia"? Kierkegaard supone que la necesidad nos iguala a todos.

"Yo, soledad y sociedad" es el quinto apartado. Hannay esta vez vincula a Kierkegaard con Sartre, quién era profundamente ateo y buscó la compañía intelectual de Kierkegaard. El punto de unión, señala Hannay, es la potencia y virulencia con la que el danés introdujo al individuo en el discurso filosófico. Más aún, el impulso martírico del sujeto kierkegaardiano se complementa con el materialismo dialéctico de Marx. El juego entre interioridad y situación histórica les vale a Kierkegaard y a Marx el peso de sus legados. Esta suposición le sirve a Hannay para arribar a la cuestión del individuo y la sociedad. El creyente lucha en su descubrimiento de la incertidumbre existencial. Esta batalla, dice Hannay citando a Bernard Williams, puede ser comprendida como un "proyecto fundacional"s de integridad personal. En este sentido, Kierkegaard va a contrapelo de la política de la identi- dad. En ésta, los individuos dirigen sus intereses vitales en identidades colectivas que buscan el voto de la mayoría. La unidad social universal se repele por ser una igualdad que borra las diferencias. Kierkegaard, por su parte, según lo lee Hannay, busca precisamente conducir esas diferencias hacia una sociedad no sectaria. El propósito común es alcanzar ese espacio concreto, en el cual lo que nos diferencia al mismo tiempo nos iguala. De acuerdo con Hannay, "la interioridad en sentido religioso puede jugar un rol esencial en quebrar la atrincherada división de las lealtades políticas". ' Hannay acota que la interioridad es aquí más cercana a la sinceridad que al puro aislamiento. Reafirma hacia el final: "Sería precipitado, e incluso peligroso, inferir que la fe cristiana [...] sea una cura general para ausencia de armonía social". ${ }^{10}$

El sexto y conclusivo capítulo es "Comparaciones". Hannay contrapone el proyecto evangelizador de Kierkegaard con la diversidad de identidades que habitan en la sociedad

\footnotetext{
Hannay, Kierkegaard, 57.

Hannay, Kierkegaard, 73.

Hannay, Kierkegaard, 79.

Hannay, Kierkegaard, 82.
} 
contemporánea. Si bien la producción kierkegaardiana asume la complejidad humana, todo converge en el fin más perfecto del cristianismo. Así, el filósofo danés no parece muy pertinente para el desafío político actual. Sin embargo, Hannay de inmediato redirige la mirada hacia Kierkegaard mismo: el proceso a través del cual este último llega al cristianismo como redentor individual, es precisamente la búsqueda personal de un sustento ante las incertidumbres existenciales. El desfile de seudónimos, dice Hannay, encarna el proceso de subjetivación y se vuelve "una cuestión de enfrentar la paradoja". ${ }^{11}$ Hannay no se aventura a defender que el ejemplo de Kierkegaard sea la solución definitiva a la división social, pero sí asume, a través del foco kierkegaardiano en la existencia y luego en el cristianismo, que el reconocimiento y el sentido personal tienen un rol en los asuntos humanos.

En los últimos cuarenta años se han generado dos formas de usar a
Kierkegaard como un autor pertinente para el pensamiento sociopolítico. La primera declara que el aspecto religioso de su pensamiento es central para su política. La segunda se desliga del factor trascendental tradicional y lo reemplaza por uno de corte más transversal (por ejemplo, Dios muta en el absoluto). Me parece que Hannay introduce una tercera modulación. Si bien el cristianismo es el centro de su análisis, hay un énfasis en la duda radical, desde la cual emana como salvación. Síntoma de esto resulta que Hannay traiga a colación a Montaigne — un ateo- y a Tolstoi — un cristiano racionalista-, y los hace dialogar con Kierkegaard. La conclusión parece ser que, en mayor o menor medida, los excluidos de los cánones sociales terminan diciendo algo sobre la misma sociedad.

En un esfuerzo con más intuiciones que propuestas, Hannay abre un camino para revitalizar el trabajo hermenéutico de Kierkegaard en filosofía política. 